\title{
FUNGAL POPULATION, AFLATOXIN AND FREE FATTY ACID CONTENTS OF PEANUTS PACKED IN DIFFERENT BAG TYPES
}

\author{
SONIA S.P. BULAONG \\ Natural Sciences Research Institute, University of the Philippines, \\ Diliman, Quezon City, Philippines \\ OKKY S. DHARMAPUTRA \\ SEAMEOBIOTROP, P.O. Box 116, Bogor, Indonesia and \\ Faculty of Mathematics and Natural Sciences, Bogor Agricultural University, Bogor, \\ Indonesia
}

\begin{abstract}
Shelled peanuts of Gajah var. with initial moisture content of $7 \%$ were stored at $11 \mathrm{~kg} / \mathrm{bag}$ in four bag types namely: jute bag, polypropylene bag, jute bag doubled with thin polyethylene (PE), and jute bag doubled with thick PE. Storage was done for six months under warehouse conditions with monitoring of relative humidity and temperature. Samples taken at the beginning of storage and every month thereafter were analyzed for moisture content, fungal population, aflatoxin and free fatty acid contents. Statistical analyses showed that moisture content, fungal population, and free fatty acid contents were significantly higher in jute and polypropylene bags than in PE-dou,bled jute bags. No significant differences were obtained in aflatoxin contents among bag types but at the end of six months storage, toxin level in jute bag exceeded the $30 \mathrm{ppb}$ limit. Polypropylene had second highest toxin level at 23 ppb. The PE-doubled bags had 17 and $19 \mathrm{ppb}$ total aflatoxins for thin and thick films, respectively. The results indicated that the immediate packaging of dried shelled peanuts at safe moisture level in plastic films with water vapor transmission rated of $1 \mathrm{~g} / \mathrm{m}^{2} / 24 \mathrm{hr}$ or lower is recommended. This packaging will delay critical increases in moisture content, fungal population, aflatoxin and free fatty acid contents of peanut kernels at ambient storage conditions.
\end{abstract}

Keywords: Peanuts / bag types / fungal population / aflatoxin content / free fatty acid content.

\section{INTRODUCTION}

Peanuts (Arachis hypogaea L.) is a valuable source of protein and fats for human and livestock. In 2000 the production of peanuts in Indonesia was 718000 tons (BPS 2001). Peanuts are subject to various types of deterioration during storage. One cause of deterioration is fungal growth which makes the material unacceptable to consumers.

Storage fungi can cause decrease of germination capability, loss in weight, discoloration of kernels, heating and mustiness, chemical and nutritional changes, and mycotoxin contamination (Sauer et al. 1992). They can change fat quality of peanuts by hydrolytic enzymes producing free fatty acids and glycerol (Pomeranz 1992). Altogether, these changes lead to a lower quality or rejection of commodity 
as foodstuff. Three fungal species, namely Aspergillusflavus, A. parasiticus, and A. nomius produce aflatoxins as secondary metabolites (Pitt and Hocking 1997). The toxins are known to be carcinogenic, hepatotoxic and teratogenic in test animals.

Based on the report of the $23^{\text {rd }}$ session of the Joint FAO/WHO Food Standards Programme, held in Rome, Italy, 28 June - 3 July 1999, Codex Alimentarius Commission adopted the maximum level of $15 \mathrm{ppb}$ for total aflatoxins in peanuts intended for further processing.

The problem of fungal growth and aflatoxin contamination of foodstuffs remains, especially in developing countries where handling and storage technologies are still being developed. Pitt and Hocking (1996) reported that aflatoxin exceeding 50 ppb contaminated 45, 22 and 25\% of 215, 81 and 94 peanut samples collected from retailers in 1990/1991 in Indonesia, Philippines and Thailand, respectively. In line with this study Lubulwa and Davis (1994) reported that the total annual cost of aflatoxin contamination in Indonesia, Philippines and Thailand was about \$A 158 million. Indonesia incurred 84\% (= \$A 132 million) of this cost, Thailand incurred 13\% (= \$A 21 million) and Philippines 3\% (= \$A 5 million) of the cost.

Moisture content is the most important factor affecting fungal growth in stored products. Peanuts are stable at $70 \%$ relative humidity between 7 - 9\% moisture content, at which conditions fungal growth is arrested (ICAR 1987). When the product absorbs moisture from the environment or when the relative humidity exceeds the equilibrium $\mathrm{RH}$ of the kernels, fungal growth occurs. For storage, therefore, the packaging material used should have a water vapor transmission rate (WVTR) low enough to minimize moisture absorption from the environment.

In commercial practice, 2 types of bags are commonly used to store peanuts, i.e. jute and polypropylene bags. Jute bags easily absorb moisture but allow good airflow. Polypropylene is non-absorptive but tends to trap heat inside (Kennedy and Devereau 1994). The ability of polyethylene (PE) bags, singly or in combination with polypropylene to inhibit fungal growth and aflatoxin production in wet corn for two weeks has been reported (Siriacha et al. 1990). Peanut kernels packed in PE bags then stored in jute bags were found to remain viable up to 7 months of storage (Reddye/fl/. 1992).

The objectives of this study were to determine the effects of different bag types on fungal population, aflatoxin and free fatty acid contents of stored peanuts together with change in moisture content. The effects of storage duration on the changes in the parameters mentioned above were also determined.

\section{MATERIALS AND METHODS}

\section{Methods of harvesting, drying and shelling of peanut}

The peanut used in this study was the "Gajah" variety, a cross between Schwarz and Spanish lines. The plants were cultivated in the Citayam farm of the Research Institute for Food Crop Biotechnology, Bogor, Indonesia. It was harvested 
100 days after sowing. The pods were stripped from plants and sundried to moisture content of about $8 \%$. Pods were shelled manually to minimize damage to kernels. Before storage, shelled peanuts were fumigated with phosphine for 5 days at 2 grams/ton to control insect pests that may exist. Prior to bagging, damaged or moldy kernels were hand picked from the batch.

\section{Storage of peanut}

Shelled peanuts with initial moisture content of about $7 \%$ were packed at $11 \mathrm{~kg} / \mathrm{bag}$ in 0.42 m x 0.47 m bags. The bag types used were (1) jute bag (JB), (2) polypropylene bag (PB), (3) jute bag doubled with thin polyethylene (PE) bag (JB+1), and (4) jute bag doubled with thick PE bag (JB+2). The physical properties of the PE bags are given in Table 1 .

Table 1. Laboratory analysis of polyethylene films *

\begin{tabular}{lccc}
\hline \hline & $\begin{array}{c}\text { Thickness } \\
(\mathrm{mm})\end{array}$ & $\begin{array}{c}\text { Water Vapor Transmission } \\
\text { Rate (WVTR) } \\
\left(\mathrm{g} / \mathrm{m}^{2} / 24 \mathrm{hr}\right)\end{array}$ & $\begin{array}{c}\text { Oxygen Transmission Rate } \\
(\text { OTR }) \\
\left(\mathrm{cc} / \mathrm{m}^{2} / 24 \mathrm{hr}\right)\end{array}$ \\
\hline Thin PE film & 0.033 & 3.84 & 1194.8 \\
Thick PE film & 0.151 & 1.16 & 71.1 \\
\hline
\end{tabular}

* Analyzed by the Institute for Research and Development of Chemical Industry, Jakarta, Indonesia

Each bag type (treatment) was replicated 3 times (4 bags per replication or stack). Each stack was arranged randomly and placed upright on wooden pallets. The bags were stored under warehouse conditions for 6 months. Ambient temperature and relative humidity were recorded using a Wilh. Lambercht thermo-hydgrograph type 252.

\section{Sampling method}

Samples were taken from each bag at the beginning of storage and subsequently every month thereafter until 6 months storage. Initial samples were taken from 3 points (top, middle and bottom) in each bag using a sampling spear. Every sampling, the samples were taken from the same points. About 250 grams samples from each bag in a stack were mixed homogeneously to get a 1000 gram primary sample. The primary sample was divided twice using a sample divider to obtain working samples for moisture content, fungal population, aflatoxin and free fatty acid contents. A 500 gram portion was set aside as reserved sample. Samples for fungal population were refrigerated until analysis. Samples for aflatoxin and free fatty acids tests were frozen until analysis. Moisture content was carried out on the day of sampling. Samples were analysed in duplicates. 


\section{Moisture content analysis}

Moisture content of kernels was determined using oven method (BSI 1980), 2 replicates per sample. The kernels were ground and dried in an oven at $130^{\circ} \mathrm{C}$ for 2 hours. The moisture content was calculated using the following formula:

$$
\begin{aligned}
& \text { Moisture content (\% wet basis) }=\frac{\left(\mathrm{M}_{0}-\mathrm{M}_{1}\right)}{\mathrm{M}_{0}} \times 100 \\
& \text { where } \quad \mathrm{M}_{0}=\text { initial weight, in grams of test portion } \\
& \qquad \mathrm{M}_{1}=\text { final weight, in grams of dried test portion }
\end{aligned}
$$

\section{Determination of fungal population}

The dilution method followed with pour-plating using Dichloran 18\% Glycerol Agar (DG18) (Pitt and Hocking 1997) was adopted. A 25 gram sample was ground for 2 minutes and mixed with $225 \mathrm{ml}$ sterile distilled water to make an initial dilution of $10^{\prime \prime}{ }^{1}$. This initial suspension was shaken manually for 2 minutes, then settled for 30 seconds before aliquots were taken from the surface. Dilutions from $10^{\prime 2}$ and higher were shaken for 1 minute before sampling. Platings were done from $10^{\prime \prime}$ to $10^{\prime \prime}$ at the beginning and after 1 month of storage. Later samplings were plated up to $10^{\prime \prime}$ dilution. Four replicate plates were used per dilution. Plates were incubated at ambient temperature for 6 days. Populations of individual species were determined using the following formula:

$$
\begin{aligned}
& \text { Population of fungal species (wet basis) }=\frac{1}{\mathrm{X} \cdot \mathrm{Y}} \mathrm{Z} \\
& \text { where } \quad \begin{array}{c}
\mathrm{Z}=\text { average number of colonies from } 4 \text { plates } \\
\mathrm{X}=\text { dilution that produced separate fungal colonies } \\
\mathrm{Y}=\text { amount of aliquot plated }
\end{array}
\end{aligned}
$$

The fungal populations at wet basis were converted to their values at dry basis using the following formula (Fardiaz 1989).

Population of species (wet basis) $\times 25$

Population of fungal species (dry basis) $=$

$$
25\left\{\frac{\text { (moisture content of sample wet basis) } \times 25}{100}\right\}
$$




\section{Aflatoxin analysis}

The thin layer chromatography (TLC) method of Blaney et al. (1984) was used for aflatoxin analysis. A 10 gram portion of ground peanut was mixed with $50 \mathrm{ml}$ acetonitrile, $5 \mathrm{ml}$ 4\% KCL and $1 \mathrm{ml} \mathrm{5 \%} \mathrm{HCL}$. The mixture was stirred for 45 minutes over a magnetic stirrer. The mixture was filtered and defatted twice with $25 \mathrm{ml} \mathrm{n}$-hexane in a separator/ funnel. The acetonitrile phase was extracted with two $(25 \mathrm{ml})$ portions of dichloromethane. Water was removed by filtering through 2 gm anhydrous sodium sulphate into a round-bottom flask. Dichloromethane extract was evaporated to dryness on a rotary evaporator. The residue was dissolved in $0.5 \mathrm{ml}$ chloroform and spotted on TLC plate at $20 \mathrm{uJ}$ per spot. A series of standard solutions of aflatoxin Bj, $\mathrm{B}_{2}$, GI and $\mathrm{G}_{2}$ were spotted on the same plate for comparison. The plates were developed in a chamber containing chloroform: acetone (9:1). Plates were air-dried and viewed under UV $366 \mathrm{~nm}$. Aflatoxin concentration was calculated using the following formula (Bainton et al. 1980):

$$
\begin{aligned}
& \text { Aflatoxin concentration }(\mathrm{ppb})=\frac{\mathrm{S} \cdot \mathrm{Y} \cdot \mathrm{V}}{\mathrm{W} \cdot \mathrm{Z}} \\
& \text { where } \mathrm{S}= \mu \mathrm{l} \text { of aflatoxin standard which gave nearest fluorescence to } \\
& \text { sample } \\
& \mathrm{Y}= \text { concentration of aflatoxin standard in } \mu \mathrm{g} / \mathrm{ml} \\
& \mathrm{V}= \text { final volume of sample extract spotted on plate which gave } \\
& \text { nearest intensity of fluorescence as } \mathrm{S}
\end{aligned} \mathrm{W}
$$

\section{Free fatty acid analysis}

The titration method of Joslyn (1970) for peanut oil was adopted. Peanut oil was extracted from a 30 gram sample using a Soxhlet apparatus. A 10 gram portion of oil was dissolved in hot $100 \mathrm{ml}$ neutralized ethanol. The solution was titrated using $0.1 \mathrm{~N} \mathrm{NaOH}$ solution with phenolpthalein indicator. Free fatty acid was calculated as oleic acid and reported as fatty acid value (FAV) or $\mathrm{mg} \mathrm{KOM} / \mathrm{g}$ sample.

\section{Statistical analysis}

The data were analyzed using a completely randomized factorial design with two factors. The first and second factors were bag type and duration of storage, respectively. 


\section{RESULTS AND DISCUSSION}

\section{The effect of bag type and duration of storage on moisture content}

Based on statistical analysis, type of bags, duration of storage and their interaction gave very significant differences on moisture content of peanut kernels (Table 2). At 95\% confidence level, the moisture contents (m.c.) in both polypropylene bag (PB) and jute bag (JB) were significantly higher than m.c. in jute bag doubled with thin $\mathrm{PE}(\mathrm{JB}+1)$ and jute bag doubled with thick PE (JB+2) (Table 3). The m.c. of JB and PB were not significantly different but significant difference exists between m.c. of $\mathrm{JB}+1$ and $\mathrm{JB}+2$. The m.c. of peanut kernels packed in JB, PB, $(\mathrm{JB}+1)$ and $(\mathrm{JB}+2)$ were 8.23, 8.26, 7.55 and $7.49 \%$, respectively.

Table 2. Analysis of variance on the effect of bag type, duration of storage and their interaction on moisture content, fungal population, total aflatoxin and free fatty acid contents of peanuts

\begin{tabular}{|c|c|c|c|c|}
\hline \multirow[b]{2}{*}{ Source } & \multicolumn{4}{|c|}{ F value } \\
\hline & $\begin{array}{c}\text { Moisture } \\
\text { content }(\% \mathrm{db})\end{array}$ & $\begin{array}{c}\text { Fungal } \\
\text { population (log } \\
\mathrm{cfu} / \mathrm{g}, \mathrm{db})\end{array}$ & $\begin{array}{l}\text { Total aflatoxin } \\
\text { content (ppb) }\end{array}$ & $\begin{array}{l}\text { Free fatty acid } \\
\text { content }(\mathrm{g}, \mathrm{db})\end{array}$ \\
\hline Bag type (A) & $445.84^{* *}$ & $1150.91^{* *}$ & 0.75 & $50.07 * *$ \\
\hline $\begin{array}{l}\text { Duration of storage } \\
\text { (B) }\end{array}$ & $946.46^{* *}$ & $1810.36 * *$ & $26.82 * *$ & $127.02 * *$ \\
\hline$A \times B$ & $95.23 * *$ & $584.16^{* *}$ & 1.34 & $33.04 * *$ \\
\hline
\end{tabular}

$* *=$ very significantly different at $99 \%$ confidence level

The lack of significant difference between m.c. in JB and PB suggests that moisture transfers through both types of packaging were at similar rates. As expected, JB+2 had lower m.c. than JB+1 due to its lower WVTR. The difference between m.c. in plastic-doubled bags was only $0.06 \%$. This slight yet significant difference might be due to the condition of the bags during storage. Since sampling was done by spear method, 3 points on one side of each bag were punctured at the start of storage. These openings were covered with a plastic tape which shrank with time and did not completely sealed the holes. At these points, the kernels were exposed to the ambient. Under this condition, $\mathrm{JB}+1$ and $\mathrm{JB}+2$ bags increased to $1.04 \%$ and $0.87 \%$ m.c., respectively during 6 months of storage (Table 3). The critical m.c. for peanuts at which $A$. flavus grows and produces aflatoxin is at $9-10 \%$ corresponding to water activity (Aw) of 0.85 (WHO 1979). Based on these results, $\mathrm{JB}+2$ is the better packaging material since it allowed less moisture increase from the initial $7 \%$ m.c. of the kernels. Bulaong (1998) reported that at $25^{\circ} \mathrm{C}$ the sorption isotherm of peanut kernels var. Gajah approximates the isotherm of other 
peanut varieties. At this temperature and ERH of $85 \%$, the kernels of peanuts var. Gajah have an equilibrium moisture content (EMC) of about $12.5 \%$.

The m.c. in the different bags changed significantly with duration of storage (Table 3). From the start of storage until month 2 the m.c. were relatively constant. Significant increases were observed from month 3 until month 6 . The slight insignificant decrease in m.c. during months 1 and 2 could be due to the low RH -high temperature in the warehouse during the dry season (Appendix 1). The vapor pressure (v.p.) of the kernels might have been higher than the v.p. of the surrounding air inside the warehouse. Upon the onset of the wet season in month 3 , significant increases in m.c. were observed. The respective means of m.c. for months $0,1,2,3,4,5$ and 6 were 7.20, 7.17, 7.12, 7.60, 8.42, 8.74 and $8.97 \%$, respectively.

Table 3. The effect of bag type, duration of storage and their interaction on moisture content of peanuts

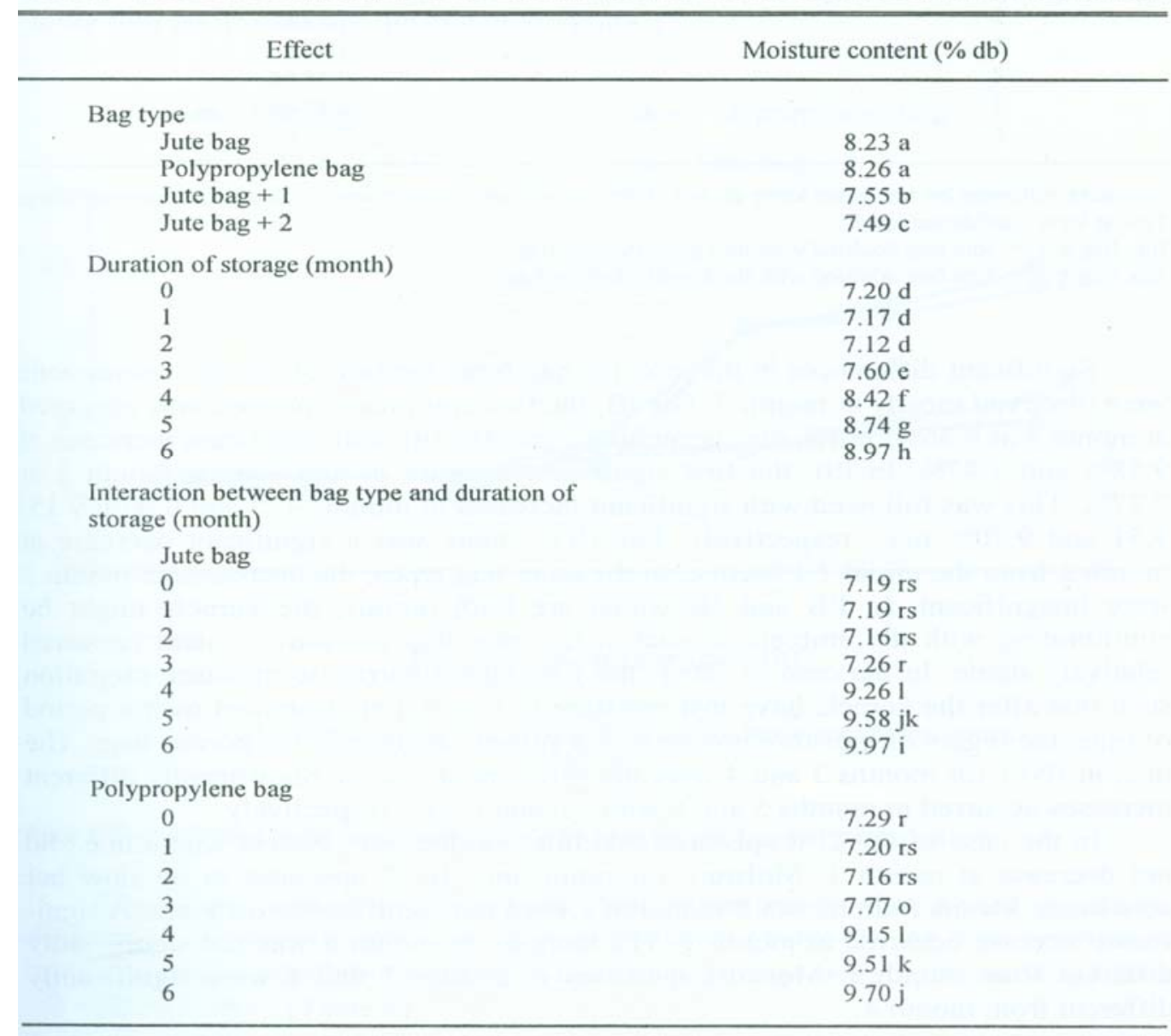


BIOTROPIA NO. 19,2002

Table 3. (Continued)

\begin{tabular}{cl}
\hline \hline Effect & Moisture content (\% db) \\
\hline Jute bag +1 & $7.19 \mathrm{rs}$ \\
0 & $7.05 \mathrm{st}$ \\
1 & $6.98 \mathrm{t}$ \\
2 & $7.71 \mathrm{op}$ \\
3 & $7.71 \mathrm{op}$ \\
4 & $8.00 \mathrm{n}$ \\
5 & $8.23 \mathrm{~m}$ \\
6 & \\
Jute bag & $7.12 \mathrm{rst}$ \\
0 & $7.22 \mathrm{rs}$ \\
1 & $7.19 \mathrm{rs}$ \\
2 & $7.48 \mathrm{q}$ \\
3 & $7.58 \mathrm{pq}$ \\
4 & $7.87 \mathrm{no}$ \\
5 & $7.98 \mathrm{n}$ \\
\hline
\end{tabular}

Numbers followed by the same letter do not differ significantly according to Duncan's Multiple Range Test at $95 \%$ confidence level.

Jute bag $+1=$ jute bag doubled with thin polyethylene bag

Jute bag +2 = jute bag doubled with thick polyethylene bag

Significant differences in the m.c. for bag type-duration of storage interactions were observed mostly at month 3. For JB, the first significant increase was observed at month 4 at $9.26 \%$. In JB, the succeeding 2 months still had significant increases at 9.58\% and 9.97\%. In PB, the first significant increase in m.c. was at month 3 at $7.77 \%$. This was followed with significant increases in months 4, 5 and 6 with 9.15, 9.51 and 9.70\% m.c., respectively. For JB+1, there was a significant decrease at month 2 from the initial 7.19\% m.c. In the other bag types, the decreases in month 2 were insignificant. In PB and JB which are both porous, the kernels might be equilibrating with the .ambient at such a fast rate that moisture content appeared relatively stable. In the case of $\mathrm{JB}+1$, the film puts a barrier to moisture migration such that after the kernels have lost moisture to low $\mathrm{RH}$ environment over a period of time, the regain of moisture proceeds of a slower rate than in the porous bags. The m.c. in JB+1 for months 3 and 4 were not different at $7.71 \%$. Significantly different increases occurred in months 5 and 6 with 8.0 and $8.23 \%$ respectively.

In the case of $\mathrm{JB}+2$, it appeared that this was the only system where m.c. did not decrease at month 1. Moisture migration into $\mathrm{JB}+2$ appeared to be slow but consistent. Means from month 0 to month 2 were not significantly different. A significant increase occurred at month 3 . The increase in month 4 was not significantly different from month 3. Moisture increases in months 5 and 6 were significantly different from month 4 . 
At month 6, the final m.c. in the bags were significantly different with $\mathrm{JB}>\mathrm{PB}>\mathrm{JB}+1>$ $\mathrm{JB}+2$, they were 9.97, 9.70, 8.23 and 7.98\%, respectively (Table 3).

The results suggested that moisture migration through JB was faster than at PB. This may be due to the difference in pore size and permeability of the 2 bags. $\mathrm{PB}$ is made of synthetic material less absorbent than jute fiber. As expected, $\mathrm{JB}+1$ allowed more moisture migration than $\mathrm{JB}+2$ because of its higher WVTR.

Of all the bag types, $\mathrm{JB}+2$ showed consistent but slow increase in m.c. during storage. Moisture increases in JB and PB were drastic at the times $\mathrm{RH}$ was high. Moisture content in $\mathrm{JB}+1$ during these months of high $\mathrm{RH}$ also significantly increased at 8 and $8.23 \%$ for months 5 and 6, respectively. At the same period, $\mathrm{JB}+2$ did not have significant moisture increase.

With the final moisture content of $9.97 \%$, jute bag was already within the critical moisture limit of $9-10 \%$ for peanuts. JB+2 with final $7.98 \%$ was still in save moisture level for storage up to six months. The changes in m.c. during storage in the four treatments are illustrated in Figure 1.

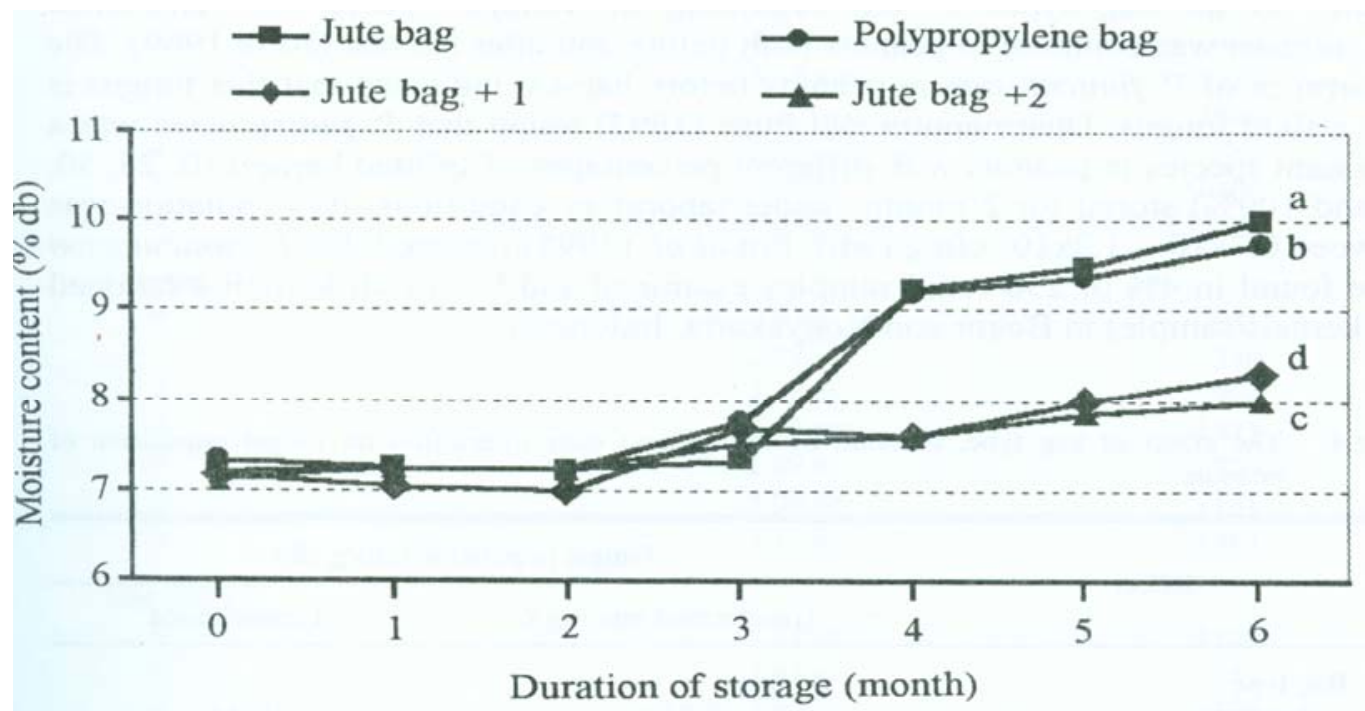

1. yure 1. Moisturc content of peanuts from various treatments during storage

\section{The effect of bag type and duration of storage on fungal population}

Bag types, duration of storage and their interaction produced very significant differences on fungal population of stored peanuts (Table 2). At 95\% confidence level, the fungal populations during 6 months of storage were in the order of $\mathrm{JB}>\mathrm{PB}>\mathrm{JB}+2>\mathrm{JB}+1$ (Table 4). 
There was a significant decrease in fungal count at month 1 . This coincided with a slight insignificant decrease in moisture content at the same month (Table 3). At months 2 and 3, the fungal population increased significantly from month 1 . The means between months 2 and 3 were not significantly different although at month 3 , the moisture content significantly increased. At month 4 was another significant decrease in the population. This occurred despite the significant increase in the moisture content at 8.42\% (Table 3). At months 5 and 6 significant increases in fungal counts coincided with ncreases in moisture content. Fungal counts were 32535 and $94856 \mathrm{cfu} / \mathrm{g}(\mathrm{db})$, respectively.

The fungi have been described to be sensitive detectors of moisture changes in stored grains. Their sensitivity was described to be comparable to sophisticated equipment (Sauer et al. 1992). The decrease in fungal count at month 1 may be attributed to the significant decrease of $0.03 \%$ moisture content (Table 3 ).

With a further (insignificant) decrease of $0.03 \%$ moisture content for month 2 , there was however a significant increase in the fungal population (Table 4). This was caused by the growth of Penicillium funiculosum which was the dominant species in all bag types at the beginning of storage (Table 5). Penicillium funiculosum was common in peanuts both before and after harvest (Joffe 1969). The occurrence of $P$. funiculosum in peanuts before harvest indicated that this fungus is also a field fungus. Dharmaputra and Putri (1997) found that $P$. funiculosum was a dominant species in peanuts with different percentages of splitted kernels $(0,25,50,75$ and 100\%) stored for 2 months under laboratory conditions. Its population was between $0.7 \times 10-1.2 \times 10^{3} \mathrm{cfu} / \mathrm{g}$ (wb). Pitt et al. (1998) reported that $P$. funiculosum were found in $4 \%$ of 256 retail samples examined and $9 \%$ of all kernels examined (50 kernels/sample) in Bogor and Yogyakarta, Indonesia.

Table 4. The effect of bag type, duration of storage and their interaction on fungal population of peanuts

\begin{tabular}{lrr}
\hline \hline & \multicolumn{2}{c}{ Fungal population (cfu/g, db) } \\
\cline { 2 - 3 } & \multicolumn{1}{c}{ Transformed into log $\mathrm{N}$} & Not transformed \\
\cline { 2 - 3 } & & \\
Bag type & $3.73 \mathrm{a}$ & 43014 \\
Jute bag & $3.56 \mathrm{~b}$ & 32959 \\
Polypropylene bag & $3.01 \mathrm{c}$ & 1073 \\
Jute bag + 1 & $3.14 \mathrm{~d}$ & 2434 \\
Jute bag + & & \\
Duration of storage (month) & $2.95 \mathrm{e}$ & 926 \\
0 & $2.75 \mathrm{f}$ & 582 \\
1 & $3.51 \mathrm{~g}$ & 5127 \\
2 & $3.50 \mathrm{~g}$ & 4454 \\
3 & $2.76 \mathrm{f}$ & 613 \\
4 & $3.85 \mathrm{~h}$ & 32535 \\
5 & $4.21 \mathrm{i}$ & 94856 \\
\hline
\end{tabular}


Fungal population, aflatoxin and free fatty acid - Sonia S.P. Bulaong \& Okky S. Dharmaputra

Table 4. (Continued)

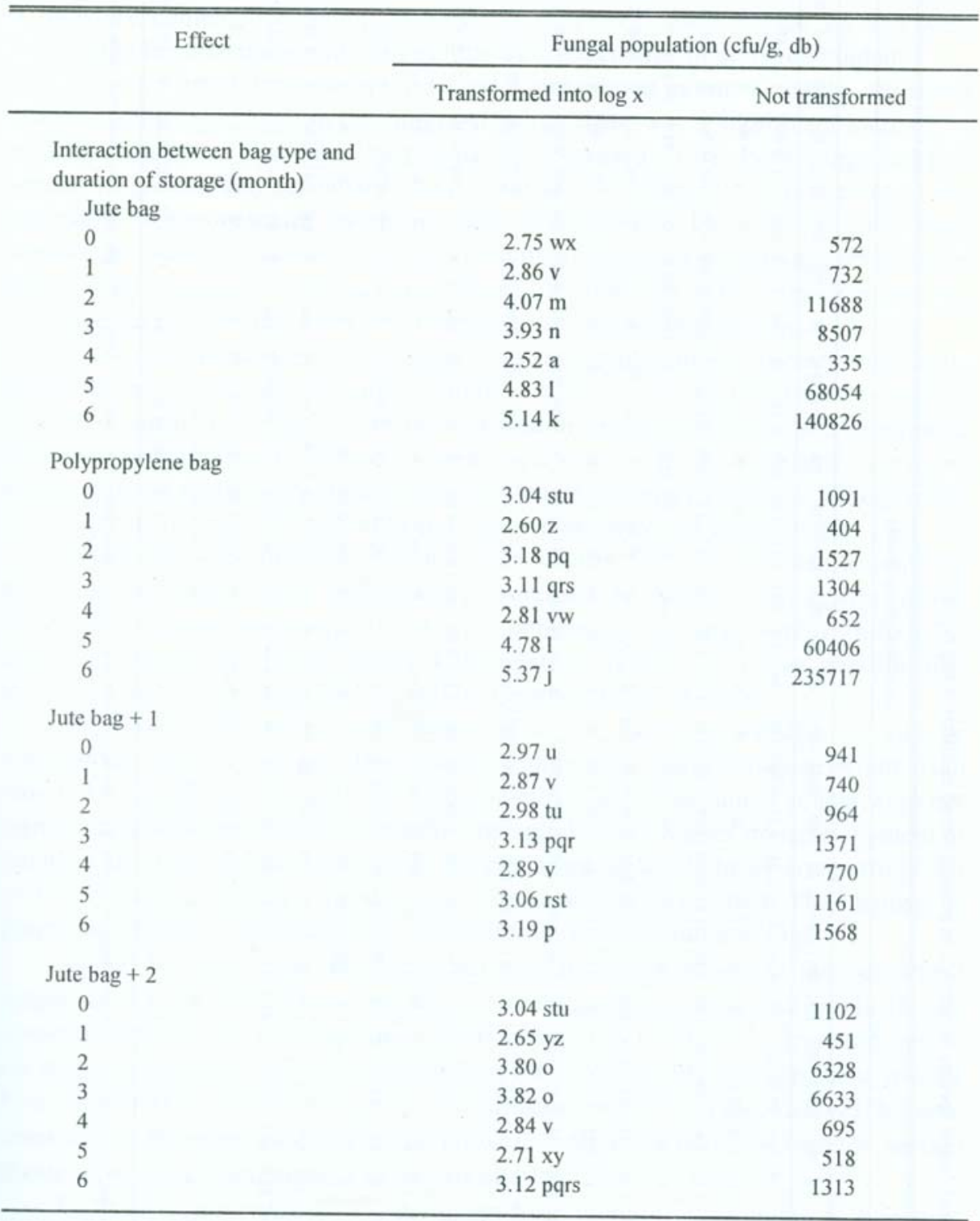

Numbers followed by the same letter do not differ significantly according to Duncan's Multiple Range Test at $95 \%$ confidence level.

Jute bag $+1=$ jute bag doubled with thin polyethylene bag

Jute bag $+2=$ jute bag doubled with thick polyethylene bag 


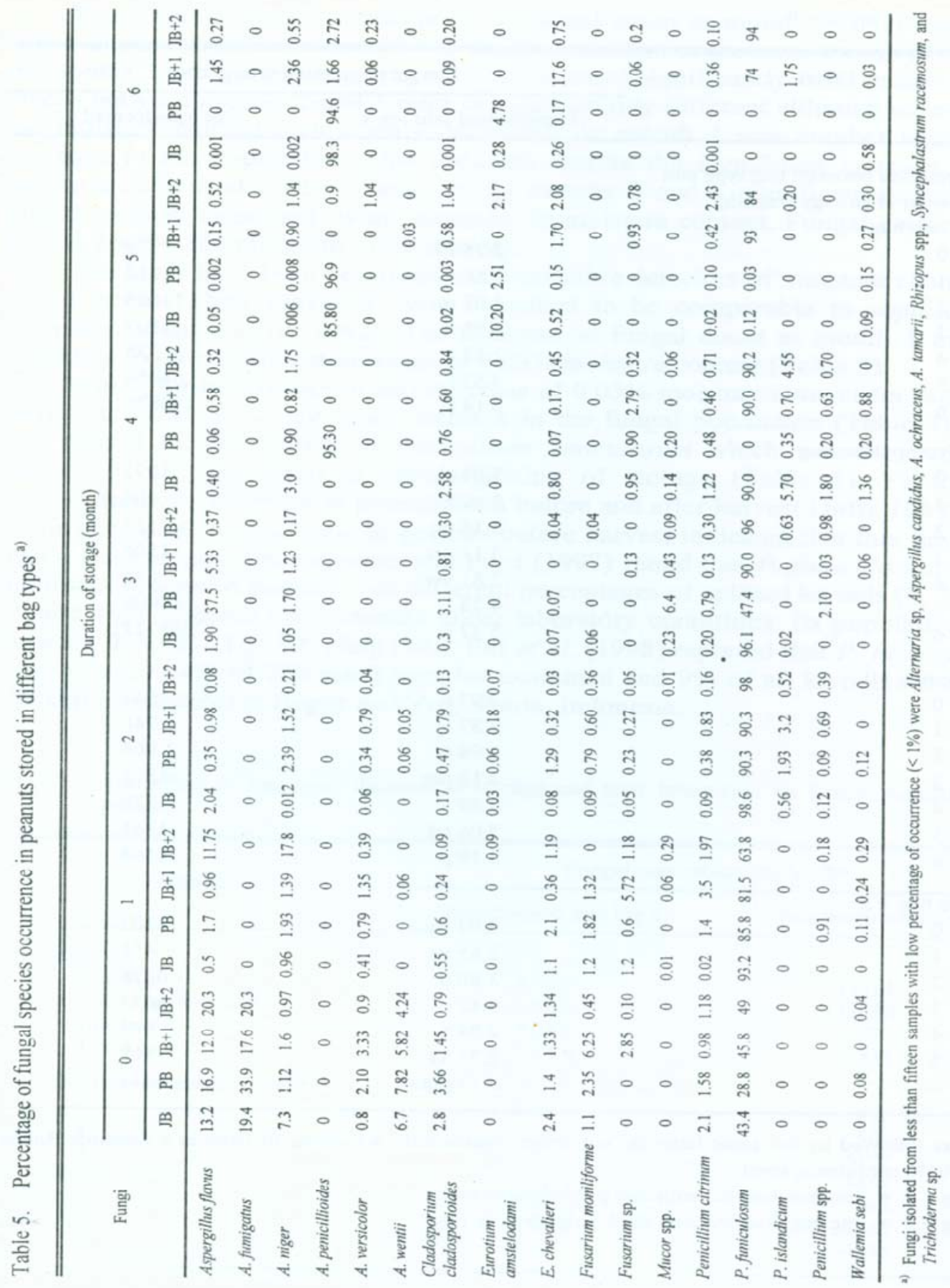


It was assumed that the dominance of $P$. funiculosum was due to a little change in moisture content. According to Sauer et al. (1992) some fungal species were observed to become dominant with as little as $0.2 \%$ change in moisture content.

The significant decrease in the fungal population at month 4 may be attributed to a physiological change in the fungi. Although there was a significant increase in moisture content at this time, the population decreased. It has been suggested that vegetative growth and secondary metabolism are two competitive processes in the life cycle of an organism (Garraway and Evans 1984). The onset of secondary metabolism, such as aflatoxin synthesis, requires additional physiological resources like moisture, enzymes and nutrients. Hence, it competes with vegetative growth. This may account for the decrease in fungal count despite moisture increase.

Secondary metabolism is triggered by accumulation of primary metabolic intermediates. These intermediates could have started in the kernels from the start of fungal colonization during pre- or post-harvest of peanuts until month 3 of storage. Secondary metabolism is viewed by some as a way for microorganisms to remove excess primary metabolites intermediates so that the primary processes, like growth, may continue in times of environmental stress (Garraway and Evans 1984).

Aflatoxins were first detected at month 4 when fungal count was lowest and the moisture content had significantly increased to $8.42 \%$. Aspergillus flavus constitutes a minor percentage of the total population, its range was from $0.001-1.45 \%$ of population during month 4 to month 6 (Table 5). It was possible that secondary metabolism occurred as well in the other fungal species.

Significant differences were observed in the bag type-duration of storage interactions. For JB, PB and JB+1, fungal counts were significantly different from month 0 to month 6 . Only at $\mathrm{JB}+2$ during months 2 and 3 the fungal counts were not significantly different (Table 4), despite the significantly higher moisture content at month 3 in $\mathrm{JB}+2$ (Table 3). It could be explained in the light of competition for moisture during secondary metabolism as discussed in earlier part. The changes in fungal population in the treatments during storage are illustrated in Figure 2.

For all bag types, the significant increases in fungal count was attributed to 2 fungal species, i.e. Penicillium funiculosum and Aspergillus penicillioides. In JB, the dominant fungus was $P$. funiculosum from month 0 to month 4 . At month 5 and 6 , the dominant species was $A$. penicillioides (Table 5). For $\mathrm{PB}$, the dominant species from month 0 to month 4 was $P$. funiculosum, while $A$. penicillioides became dominant in $\mathrm{PB}$ from month 4 to month 6 . Eurotium amstelodami was the second dominant species from month 5 to 6 in JB and PB.

In $\mathrm{JB}+1$ P. funiculosum was dominant from month 0 until month 6 . Eurotium chevalieri was the second dominant species at 1.70 and $17.6 \%$ of population for months 5 and 6 , respectively. In $\mathrm{JB}+2, P$. funiculosum was dominant from month 0 to month 6 . Eurotium chevalieri contributed 2.08 and $0.75 \%$ to total population at months 5 and 6 respectively. The changes in the fungal population in each bag type are presented in Figures 3 and 4. 

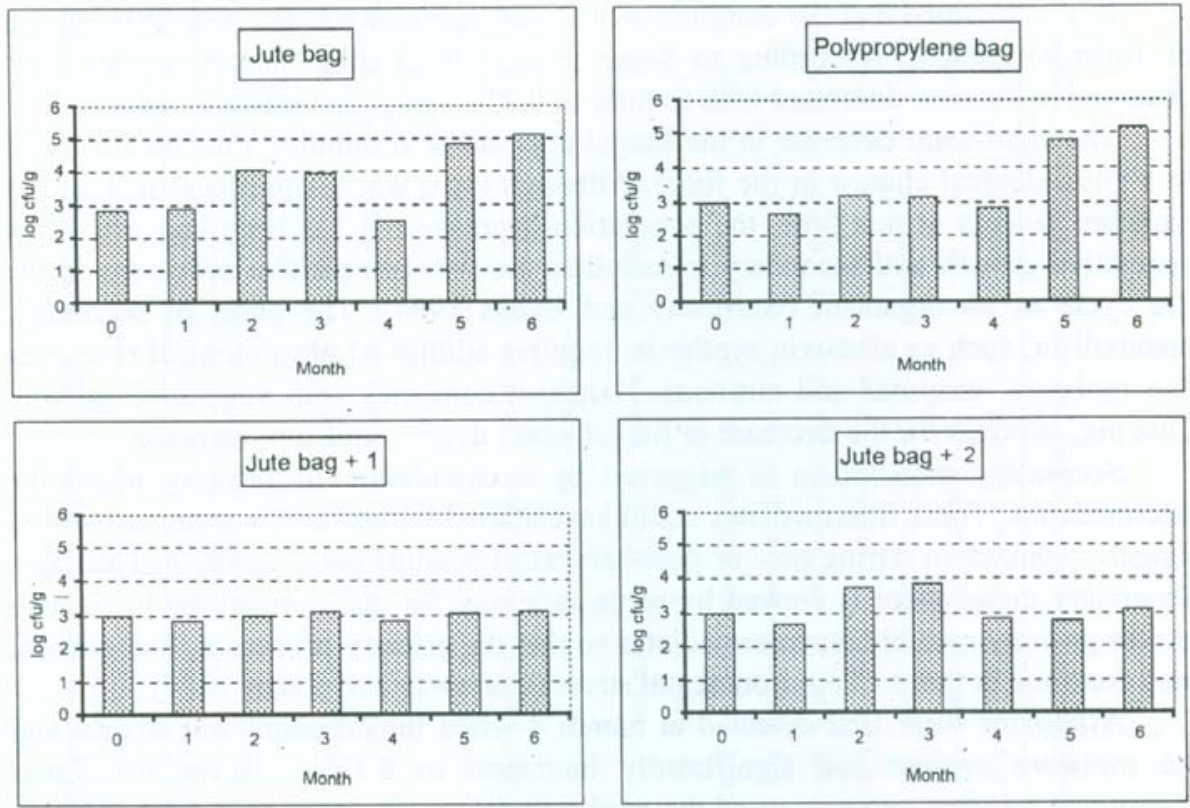

Figure 2. Total fungal populations in various treatments during storage
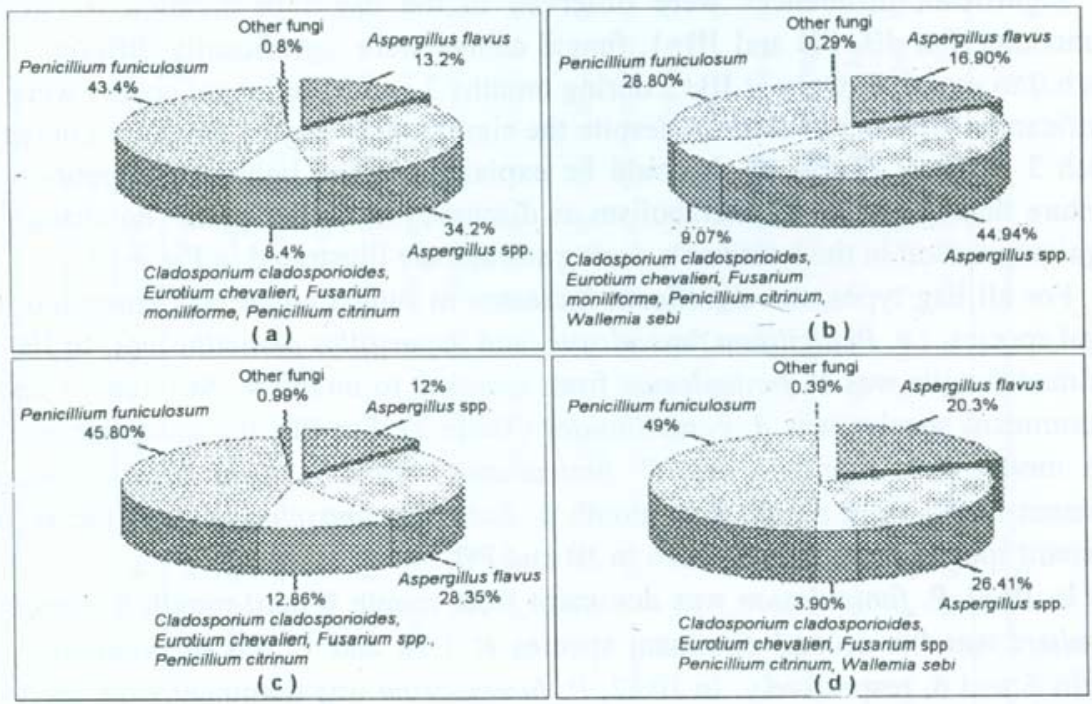

Figure 3. Percentage occurrence of fungal species at the beginning of storage in (a) jute bag, (b) polypropylene bag, (c) jute bag doubled with thin polyethylene bag, and (d) jute bag doubled with thick polyethylene bag 


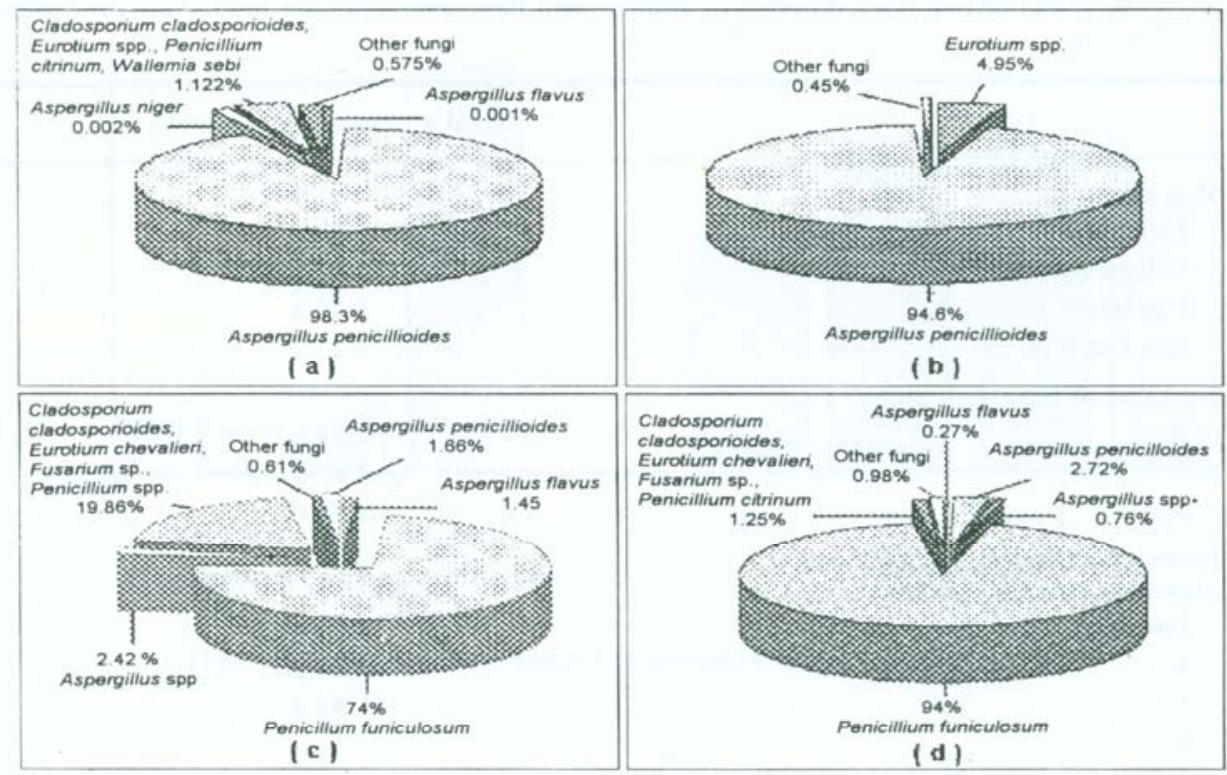

Figure 4. Percentage occurrence of fungal species at the end of 6 months of storage in (a) jute bag, (b) polypropylene bag, (c) jute bag doubled with thin polyethylene bag, and (d) jute bag doubled with thick polyethylene bag

In the complex system where several fungal species exist together, the dominance of a species may not be solely due to its ability to tolerate existing moisture conditions. Several types of interactions exist among fungi. Aside from competition for space, moisture and nutrients, there could be inhibitory interactions as well due to release of metabolites of derailing of biochemical path ways (Choudhary 1992).

The sudden succession between $P$. funiculosum and $A$. penicillioides in JB and $\mathrm{PB}$ during the latter months of storage may be due to a combination of these interactions. A possible reason for the continued dominance of $P$. funiculosum in PE-doubled bags may be its ability to compete with other species when both moisture and $\mathrm{O}_{2}$ are less than normal. Aspergillus penicillioides was observed in conditions of higher moisture content and $\mathrm{O}_{2}$ in the porous bags.

\section{The effect of bag type and duration of storage on aflatoxin content of peanuts}

Two kinds of aflatoxins were detected, i.e. aflatoxin $B I$ and $B_{2}$. Based on the analyses of variance there were no significant differences in total aflatoxin content among bag types and the interaction between bag types and duration of storage (Table 2). The means for JB, PB, JB+1 and JB +2 were 13.1, 8.9, 8.7 and 9.2 ppb, respectively (Table 6, Figure 5). 
BIOTROPIA No.19,2002

Table 6. The effect of bag type, duration of storage, and their interaction on total aflatoxin content of peanuts

\begin{tabular}{|c|c|}
\hline Effect & Total aflatoxin content (ppb) \\
\hline \multicolumn{2}{|l|}{ Bag type } \\
\hline Jute bag & $13.14 \mathrm{a}$ \\
\hline Polypropylene bag & 8.91 a \\
\hline Jute bag + 1 & $8.73 \mathrm{a}$ \\
\hline Jute bag +2 & $9.21 \mathrm{a}$ \\
\hline \multicolumn{2}{|c|}{ Duration of storage (month) } \\
\hline 4 & $2.73 \mathrm{~b}$ \\
\hline 5 & $4.69 \mathrm{~b}$ \\
\hline 6 & $22.58 \mathrm{c}$ \\
\hline \multicolumn{2}{|c|}{$\begin{array}{l}\text { Interaction between bag type and } \\
\text { duration of storage (month) }\end{array}$} \\
\hline Jute bag & $4.57 \mathrm{gh}$ \\
\hline 4 & $3.33 \mathrm{gh}$ \\
\hline 5 & $31.53 \mathrm{~d}$ \\
\hline 6 & \\
\hline \multicolumn{2}{|l|}{ Polypropylene bag } \\
\hline 4 & $3.63 \mathrm{gh}$ \\
\hline 5 & $0 \quad \mathrm{i}$ \\
\hline 6 & $23.10 \mathrm{de}$ \\
\hline \multicolumn{2}{|l|}{ Jute bag + 1} \\
\hline 4 & $2.70 \mathrm{i}$ \\
\hline 5 & $6.70 \mathrm{fgh}$ \\
\hline 6 & $16.80 \mathrm{efg}$ \\
\hline \multicolumn{2}{|l|}{ Jute bag +2} \\
\hline 4 & $0 \quad \mathrm{i}$ \\
\hline 5 & $8.73 \mathrm{fgh}$ \\
\hline 6 & $18.90 \mathrm{def}$ \\
\hline
\end{tabular}

Numbers followed by the same letter do not differ significantly according to Duncan's Multiple Range Test at $95 \%$ confidence level.

Jute bag $+1=$ jute bag doubled with thin polyethylene bag

Jute bag $+2=$ jute bag doubled with thick polyethylene bag 
Fungal population, aflatoxin and free fatty acid - Sonia S.P. Bulaong \& Okky S. Dharmaputra

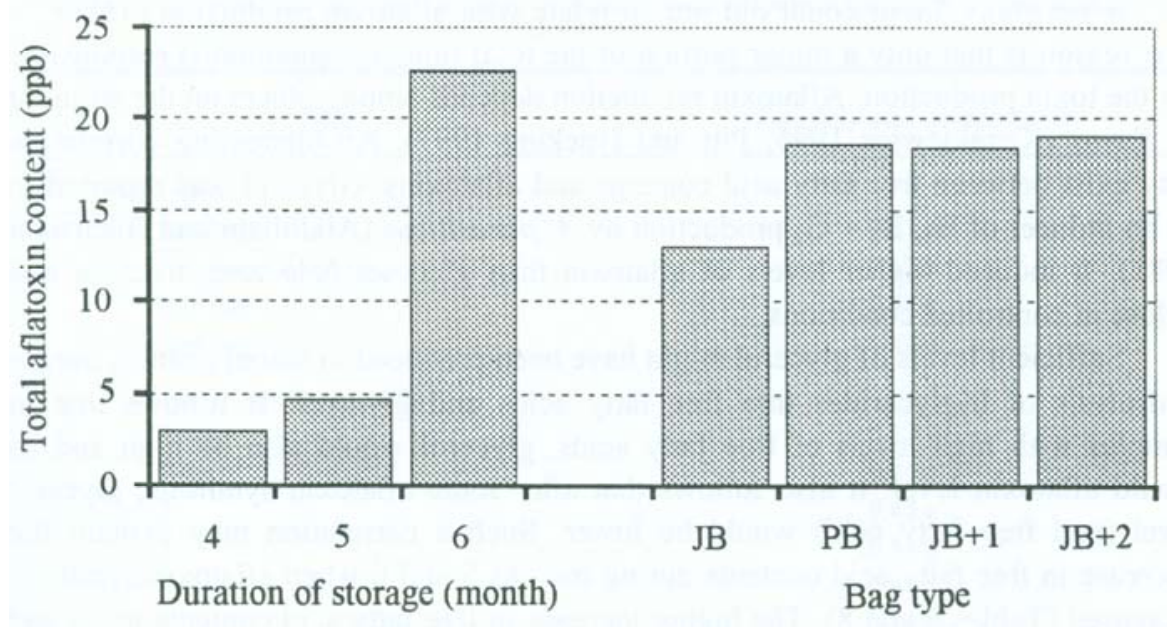

Figure 5. Total aflatoxin content of peanuts from various treatments

Aflatoxins were first detected at month 4 at concentration of $2.73 \mathrm{ppb}$. There was a significant increase to $4.69 \mathrm{ppb}$ at month 5 . At month 6, the increase to $22.58 \mathrm{ppb}$ was highly significant (Table 6, Figure 5).

At month 4, JB and PB had higher aflatoxin levels than JB+1 and JB +2. The levels were 4.6, 3.6, 2.7 and $0 \mathrm{ppb}$, respectively (Table 6). At month 5, JB+2 and $\mathrm{JB}+1$ had higher levels than $\mathrm{JB}$ and PB. The levels were 8.7, 6.7, 3.3 and 0 ppb, respectively. At month 6, JB had higher levels than $\mathrm{PB}, \mathrm{JB}+2$ and $\mathrm{JB}+1$. The values were 31.5, 23.1, 18.9 and $16.8 \mathrm{ppb}$, respectively.

Aflatoxins were not detected in the samples until month 3 of storage. It was assumed that aflatoxigenic $A$. flavus population in the soil of peanut planting field was low. The moisture content of the samples remained relatively stable from month 0 to month 2 at values $7.12-7.19 \%$ (Table 3). This moisture content corresponds to water activity of 0.65 , insufficient for aflatoxin production. Other works have reported a similar absence of aflatoxins in peanuts at low moisture content conditions. At 6.9\% m.c., aflatoxin in shelled Spanish peanuts was not detected after 8 months stored at cold storage (Wilson and Jay 1976).

Significant increases in moisture content started from month 3. At month 4, aflatoxins were detected in 3 bag types in small amounts. The moisture contents at month 4 for JB and PB were 9.26 and $0.15 \%$, respectively, within the $9-10 \%$ range, of lower limit for aflatoxin production in peanuts (WHO 1979). JB+1 at month 4 had only $7.7 \%$ moisture content yet it was positive for aflatoxin production. $\mathrm{JB}+2$ also had a moisture content less than $8 \%$ during storage, and it was positive for aflatoxins (Tables 3 and 6). It appears that aflatoxin synthesis could occur at moisture levels lower than normal range for $A$. flavus growth. 
Aspergillus flavus count did not correlate with aflatoxin production (Table 7). One reason is that only a minor portion of the total fungal population is responsible for the toxin production. Aflatoxin production depends among others on the strain of A. flavus (Kozakiewicz 1996; Pitt and Hocking 1997). An interesting correlation may exist between free fatty acid contents and aflatoxins. Glycerol was reported to be an inducer of $B_{h} B_{2}+G_{2}$ production by A. parasiticus (Abdollahi and Buchanan 1981). It induced higher levels of aflatoxin than glucose, galactose, fructose and xylose at controlled conditions.

Sufficient levels of glycerol might have been produced in stored peanuts during hydrolysis of triglycerides into free fatty acids and glycerol. It follows that in samples with high levels of free fatty acids, glycerol would also be high and so would aflatoxin level. It also follows that after some aflatoxin synthesis, glycerol level (and free fatty acid) would be lower. Such a correlation may explain the decrease in free fatty acid contents during months 5 and 6 when aflatoxin synthesis increased (Tables 6 and 8). The higher increase in free fatty acid contents in JB and $\mathrm{PB}$ from month 0 to month 3 compared with $\mathrm{JB}+1$ and $\mathrm{JB}+2$ could also result to the observed differences in aflatoxin levels of the bag types (Table 6). The role of seed lipases in free fatty acid production is discussed in the next section. The major role

Table 7. Population of A: flavus and total aflatoxin content in peanuts

\begin{tabular}{ccc}
\hline \hline Treatment & $\begin{array}{c}\text { Population of } A . \text { flavus } \\
(\mathrm{cfu} / \mathrm{g})\end{array}$ & $\begin{array}{c}\text { Total aflatoxin content }(\mathrm{ppb}) \\
\text { JB T4 }\end{array}$ \\
JB T5 & 2 & 4.5 \\
JB T6 & 2 & 3.3 \\
PB T4 & 15 & 31.5 \\
PB T5 & 2 & 3.6 \\
PB T6 & 0 & 0 \\
JB+1 T4 & 4 & 23.1 \\
JB+1 T5 & 3 & 2.7 \\
JB+1 T6 & 21 & 6.7 \\
JB+2 T4 & 3 & 16.8 \\
JB+2 T5 & 3 & 0 \\
JB+2 T6 & 3 & 18.9 \\
\hline
\end{tabular}

$\mathrm{JB}=$ jute bag $; \quad \mathrm{PB}=$ polypropylene bag

$\mathrm{JB}+1=$ jute bag doubled with thin polyethylene bag

$\mathrm{JB}+2=$ jute bag doubled with thick polyethylene bag

$\mathrm{T}_{4}=$ month $4 \quad ; \quad \mathrm{T}_{5}=$ month $5 ; \mathrm{T}_{6}=$ month 6 
Fungal population, aflatoxin and free fatty acid - Sonia S.P. Bulaong \& Okky S. Dharmaputra

Table 8. The effect of bag type, duration of storage and their interaction on free fatty acid content of peanuts

\begin{tabular}{|c|c|}
\hline Effect & Free fatty acid content $(\mathrm{g}, \mathrm{db})$ \\
\hline \multicolumn{2}{|l|}{ Bag type } \\
\hline Jute bag & $0.51 \mathrm{a}$ \\
\hline Polypropylene bag & $0.52 \mathrm{a}$ \\
\hline Jute bag +1 & $0.47 \mathrm{~b}$ \\
\hline Jute bag +2 & $0.43 \mathrm{c}$ \\
\hline \multicolumn{2}{|c|}{ Duration of storage (month) } \\
\hline 0 & $0.32 \mathrm{~d}$ \\
\hline 1 & $0.45 \mathrm{e}$ \\
\hline 2 & $0.42 \mathrm{e}$ \\
\hline 3 & $0.54 \mathrm{~g}$ \\
\hline 4 & $0.57 \mathrm{~h}$ \\
\hline 5 & $0.56 \mathrm{gh}$ \\
\hline 6 & $0.50 \mathrm{f}$ \\
\hline \multirow{2}{*}{\multicolumn{2}{|c|}{$\begin{array}{l}\text { Interaction between bag type and } \\
\text { duration of storage (month) } \\
\text { Jute bag }\end{array}$}} \\
\hline & \\
\hline 0 & $0.33 \mathrm{t}$ \\
\hline 1 & $0.51 \mathrm{mn}$ \\
\hline 2 & $0.45 \mathrm{pq}$ \\
\hline 3 & $0.54 \mathrm{~lm}$ \\
\hline 4 & $0.66 \mathrm{j}$ \\
\hline 5 & $0.61 \mathrm{k}$ \\
\hline 6 & $0.44 \mathrm{pqr}$ \\
\hline \multicolumn{2}{|l|}{ Polypropylene bag } \\
\hline 0 & $0.28 \mathrm{u}$ \\
\hline 1 & 0.48 op \\
\hline 2 & $0.41 \mathrm{qrs}$ \\
\hline 3 & $0.56 \mathrm{~lm}$ \\
\hline 4 & $0.51 \mathrm{mn}$ \\
\hline 5 & $0.62 \mathrm{jk}$ \\
\hline 6 & $0.80 \mathrm{i}$ \\
\hline \multicolumn{2}{|l|}{ Jute bag + 1} \\
\hline 0 & $0.34 \mathrm{t}$ \\
\hline 1 & $0.46 \mathrm{pq}$ \\
\hline 2 & $0.44 \mathrm{pqr}$ \\
\hline 3 & $0.53 \mathrm{~m}$ \\
\hline 4 & $0.58 \mathrm{kl}$ \\
\hline $\begin{array}{l}5 \\
6\end{array}$ & $\begin{array}{l}0.61 \mathrm{k} \\
0.37 \mathrm{st}\end{array}$ \\
\hline . & \\
\hline
\end{tabular}


Table 8. (Continued)

\begin{tabular}{cl}
\hline \hline Effect & Free fatty acid content $(\mathrm{g}, \mathrm{db})$ \\
\hline Jute bag +2 & \\
0 & $0.33 \mathrm{t}$ \\
1 & $0.37 \mathrm{st}$ \\
2 & $0.43 \mathrm{pqr}$ \\
3 & $0.53 \mathrm{~lm}$ \\
4 & $0.55 \mathrm{Im}$ \\
5 & $0.39 \mathrm{rs}$ \\
6 & $0.40 \mathrm{rs}$ \\
\hline
\end{tabular}

Numbers followed by the same letter do not differ significantly according to Duncan's Multiple Range Test at $95 \%$ confidence level.

Jute bag $+1=$ jute bag doubled with thin polyethylene bag

Jute bag $+2=$ jute bag doubled with thick polyethylene bag

of lipases in the kernels in lipid hydrolysis may offer explanation why aflatoxin occurred in $\mathrm{JB}+1$ and $\mathrm{JB}+2$ at moisture levels lower than the minimum level reported for $A$. flavus growth. The means of free fatty acids and final aflatoxins levels in each bag are illustrated in Figure 6.

\section{Fatty acid value (mg $\mathrm{KOH} / \mathrm{g}$ sample)}

\section{Total aflatoxin (ppb) at month 6 storage}

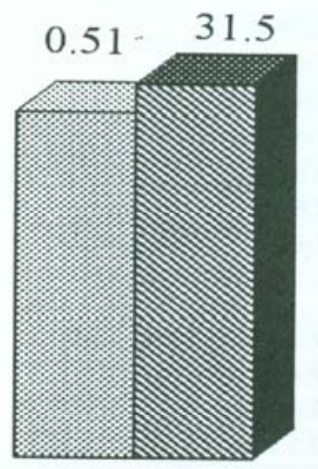

JB

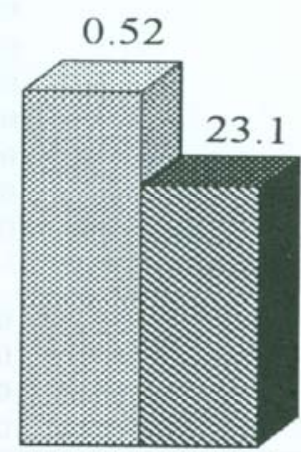

PB

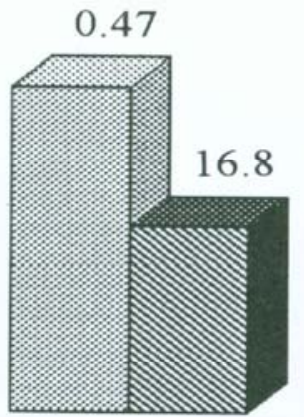

$\mathrm{JB}+1$

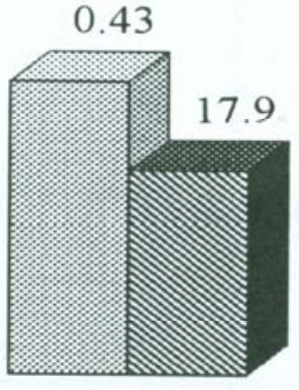

$\mathrm{JB}+2$

Figure 6. Free fatty acid and total aflatoxin contents in various treatments 
Fungal population, aflatoxin and free fatty acid - Sonia S.P. Bulaong \& Okky S. Dharmaputra

\section{The effect of bag type and duration of storage on free fatty acid contents}

Bag types, duration of storage and their interactions gave very significant differences on free fatty acid (FFA) contents of stored peanuts (Table 2). At 95\% confidence level, the FFA contents in the 4 bags were significantly different. JB and PB had insignificantly different means at 0.51 and $0.52 \mathrm{FAV}$, respectively. $\mathrm{JB}+1$ and $\mathrm{JB}+2$ had significantly different means at 0.47 and 0.43 FAV, respectively (Table 8).

Significant differences in FFA contents were observed during storage. The lowest level was at month 0 at $0.32 \mathrm{FAV}$. A significant increase to $0.45 \mathrm{FAV}$ was observed at month 1 . This was relatively unchanged until month 2 (Table 8). Significant increases were again observed in months 3 and 4 . These were followed with significant decreases in months 5 and 6 . The values for months $0,1,2,3,4,5$ and 6 were $0.32,0.45,0.42,0.54,0.57,0.56$ and $0.50 \mathrm{FAV}$, respectively.

Interactions between bag type and duration of storage resulted to significantly different FFA contents. At month 0 , the 3 bag types contained kernels with approximately same FFA contents at 0.33 - 0.34 FAV. Only PB had a significantly lower level at 0.28 FAV (Table 8). At month 1, PB had the highest increase in FFA with 0.20 FAV increase from month 0. JB had the second highest increase at month 1 with $0.18 \mathrm{FAV}$ increase from month $0 . \mathrm{JB}+1$ had 0.12 unit increase while $\mathrm{JB}+2$ had only 0.04 FAV increase. The highest increase in FFA contents in JB, PB and $\mathrm{JB}+1$ occurred at month 1 . This was followed with a significant decrease at month 2 for the same bag types. $\mathrm{JB}+2$ showed a significant increase from month 1 to month 2 . From month 3 to month 4 , significant increases were observed in $\mathrm{JB}$ and $\mathrm{JB}+1$. In $\mathrm{JB}+2$, the means for months 3 and 4 were not significantly different. In PB, there was a decrease in FFA at month 4.

Significant decreases in FFA contents were observed in JB from month 4 to months 5 and 6. In $\mathrm{JB}+1$, the decrease was observed from month 5 to month 6 . In $\mathrm{JB}+2$, the decrease was from month 4 to month 5 (Table 8).

Free fatty acids are released from the hydrolysis of triglycerides. The rapid formation of FFA during month 1 of storage for $\mathrm{JB}, \mathrm{PB}$ and $\mathrm{JB}+1$ was due to the activity of lipases in the kernels (Acker 1969; Pomeranz 1992). These Upases are known to be active even at low water activity or moisture content levels. At month 1 , moisture content was generally lower than at month 0 and the fungal population was significantly lower than month 0 (Tables 3 and 4). This is another proof that the lipase activity must be largely due to seed enzymes rather than fungal enzymes at the low moisture level. At month 2, there were significant decreases in FFA contents in $\mathrm{JB}, \mathrm{PB}$ and $\mathrm{JB}+1$. Only $\mathrm{JB}+2$ has a significant increase to $0.43 \mathrm{mg} \mathrm{KOH} / \mathrm{g}$ sample (Table 8 ). $\mathrm{JB}+2$ was the only bag system where FFA contents were more consistently increasing with duration of storage. The fluctuations in month 2 in the 3 other bag types could be attributed only to the higher permeability to $\mathrm{O}_{2}$ and moisture. During months 3 and 4, increases in FFA in JB, PB and $\mathrm{JB}+1$ were significant, but not in $\mathrm{JB}+2$. At month 5 , significant decreases were observed in $\mathrm{JB}$ 
and $\mathrm{JB}+2$. PB at month 5 regained significantly higher FFA contents compared with month 4 when it lost FFA. JB+1 at month 5 still had an increasing FFA content. At month 6, a significant drop was observed in both JB and JB+1. PB had a significant increase at month 6 to $0.80 \mathrm{FAV}$. JB+2 had an insignificant increase at month 6 to $0.40 \mathrm{FAV}$.

The possible correlation between free fatty acids and aflatoxin synthesis was discussed in the previous section. Essentially, analysis in this study indicates that high free fatty acid contents correspond to high glycerol levels since both are byproducts of lipid hydrolysis. Since glycerol induces aflatoxin synthesis, a bag system with high free fatty acid may also produce high levels of aflatoxin. This appears to be true in the case of JB and PB which had the highest initial increases in FFA content at month 1. Table 6 shows that at month 6, peanuts packed in JB had the highest aflatoxin content at $31.5 \mathrm{ppb}$. PB had the second highest content at $23.1 \mathrm{ppb} . \mathrm{JB}+1$ and $\mathrm{JB}+2$ with less increase in FFA at month 1 had 16.8 and $18.9 \mathrm{ppb}$ of aflatoxin, respectively.

It appears from the analysis of data that a packaging relatively impermeable to $\mathrm{O}_{2}$ and moisture would allow slower lipid hydrolysis than porous materials. In this respect, it may be concluded that immediate packing of peanuts in protective films may be a way to slow down aflatoxin production in peanuts.

\section{CONCLUSIONS}

The use of polyethylene lining in jute bags effected lower moisture gains than either jute or polypropylene bag alone in peanut storage. In the order of decreasing moisture gains $\mathrm{PB}>\mathrm{JB}>$ $\mathrm{JB}+1>\mathrm{JB}+2$.

The dominant fungal species found in peanuts during storage were Aspergillus penicillioides and Penicilliumfuniculosum. Bag type and duration of storage caused significant differences in fungal populations both in quantity and quality. In the order of decreasing fungal populations, JB $>\mathrm{PB}>\mathrm{JB}+2>\mathrm{JB}+1$. Fungal populations generally increased with duration of storage, except at the beginning of secondary metabolism (aflatoxin synthesis).

Level of free fatty acids changed significantly according to bag type and duration of storage. In the order of decreasing free fatty acid, $\mathrm{PB}>\mathrm{JB}>\mathrm{JB}+1>\mathrm{JB}+2$.

Aflatoxin level was not significantly affected by bag type. In the order of decreasing total aflatoxin, $\mathrm{JB}>\mathrm{JB}+2>\mathrm{PB}>\mathrm{JB}+1$. Aflatoxin level changed significantly with duration of storage. In the order of decreasing aflatoxin level, month $6>$ month $5>$ month 4 . Aflatoxin level was formed at water activity and moisture content lower than previously reported. Aflatoxin level was apparently related to free fatty acid level. 
Fungal population, aflatoxin and free fatty acid - Sonia S.P. Bulaong \& Okky S. Dharmaputra

\section{RECOMMENDATION}

Shelled peanuts with moisture content of $7 \%$ should be immediately packed in polyethylene bags with water vapor transmission rate of $1 \mathrm{gm} / \mathrm{m}^{2} / 24 \mathrm{hr}$ or lower in order to preserve its quality. Such packaging will delay moisture increase, minimize fungal growth, aflatoxin production and free fatty acid formation.

\section{ACKNOWLEDGEMENTS}

The authors gratefully acknowledge the financial support of the Canadian International Development Agency (CIDA) through SEAMEO BIOTROP. We also thank the other scientists and technicians of the Laboratory of Pest and Disease Management, and Laboratory of Chemistry, SEAMEO BIOTROP who have in one way or another contributed to this research; and Dr. Gloria L. Enriquez, former Deputy Director for Programme and Marketing of SEAMEO BIOTROP for her suggestions and encouragement.

\section{REFERENCES}

Abdollahi, A. and R.L. Buchanan. 1981. Regulation of aflatoxin biosynthesis. Induction of allatoxin production by various carbohydrates. J Food Sci. 46: 633-635.

Acker, L.W. 1969. Water activity and enzyme activity. Food Tech. 23: 27-40.

Bainton, S.J., R.D. Coker, B.D. Jones, E.M. Morley, N.J. Nagler and R.L. Turner. 1980. Mycoioxin Training Manual. Tropical Products Institute, London.

Blaney, D.J., C.J. Moore and A.L. Tyler. 1984. Mycotoxins and fungal damage in maize harvested during 1982 in Far North Queensland. Austr. J. Agric. Res. 35: 463-471.

BPS. 2001. Statistik Indonesia 2000. Badan Pusat Statistik, Jakarta. In Indonesian.

BSI. 1980. Methods of test for cereals and pulses. Part 3. Determination of moisture content of cereal.-, and cereal products (routine methods). British Standards Institution. ISBN 0580114333.

Bulaong, S.S.P. 1998. Sorption isotherm of peanut kernels var. Gajah. SEAMEO BIOTROI'. Unpublished.

Choudhary, A.K. 1992. Influence of microbial co-inhibitors on aflatoxin synthesis of Aspergillus flavim on maize kernels. Letters Appl. Microb. 14: 143-147.

Dharmaputra, O.S. and A.S.R. Putri. 1997. The relation between splitted kernels and population of storage fungi in peanuts. SEAMEO BIOTROP. Unpublished.

Fardiaz, S. 1989. Food Microbiology. Inter University Center for Food and Nutrition. Bogor Agricultural University, Indonesia, p. 268.

Garravvay, M.O. and R.C. Evans. 1984. Fungal Nutrition and Physiology. John Wiley and Sons, New York. 
ICAR. 1987. Aflatoxin in Groundnut-Technologies for Better Crops. Publications and Information Division, Indian Council of Agricultural Research, New Delhi, India.

Joffe, A.Z. 1969. The mycoflora of fresh and stored groundnut kernels in Israel. Oleagineux 27: 489-491.

Joslyn, M.A. 1970. Acidimetry. In: Joslyn, M.A. (ed.). pp. 401-446. Methods in Food Analysis; Physical, Chemical and Instrumental Methods of Analysis. Academic Press, New York.

Kennedy, L. and A. Devereau. 1994. Observations on large-scale outdoor maize storage in jute and woven polypropylene sacks in Zimbabwe. In: Highley, E., E.J. Wright, H.J. Banks and B.R. Champ (eds.). pp. 290295. Proceedings of the $6^{\text {th }}$ International Working Conference on Stored-product Protection. Canberra, Australia, 1723 April 1994.

Kozakiewicz, Z. 1996. Occurrence and significance of storage fungi and associated mycotoxins in rice and cereal grains. In: Highley, E. and G.I. Johnson (eds.). pp. 18-26. ACIAR Technical Reports 37. Mycotoxin Contamination in Grains. Paper presented at the $17^{\text {th }}$ ASEAN Technical Seminar on Grain Postharvest Technology. Lumut, Malaysia, 25-27 July 1995.

Lubulwa, G. and J. Davis. 1994. Estimating the social costs of the impacts of fungi and aflatoxins in maize and peanuts. In: Highley, E., E.J. Wright, H.J. Banks and B.R. Champ (eds.). pp. 1017-1042. Proceedings of the $6^{\text {th }}$ International Working Conference on Stored-product Protection. Canberra, Australia, 17-23 April 1994.

Lubulwa, G. and J. Davis. 1996. Completed-project economic assessment of two ACIAR projects on fungi and aflatoxins: A discussion of methodology issues and some estimates of potential benefits. In: Highley, E. and G.I. Johnson (eds.). pp. 66-98. ACIAR Technical Reports 37. Mycotoxin Contamination in Grains. Paper presented at the $17^{\text {lh }}$ ASEAN Technical Seminar on Grain Postharvest Technology. Lumut, Malaysia, 25-27 July 1995.

Pitt, J.I. and A.D. Hocking. 1996. Current knowledge of fungi and mycotoxin assessment of food commodities in South East Asia. In: Highley, E. and G.I. Johnson (eds.). pp. 5-10. ACIAR Technical Reports 37. Mycotoxin Contamination in Grains. Paper presented at the 17"' ASEAN Technical Seminar on Grain Postharvest Technology. Lumut, Malaysia, 25-27 July 1995.

Pitt, J.I. and A.D. Hocking. 1997. Fungi and Food Spoilage. Blackie Academic \& Professional, London.

Pitt, J.I., A.D. Hocking, B.F. Miscamble, O.S. Dharmaputra, K.R. Kuswanto, E.S. Rahayu and Sardjono. 1998. The mycoflora of food commodities from Indonesia. Journal of Food Mycology 1(1): 41-60.

Pomeranz, Y. 1992. Biochemical, functional and nutritional changes during storage. In: Sauer, D.B. (ed.). Storage of Cereal Grains and Their Products. Amer. Assoc. Cereal Chemists, Inc. St. Paul, Minnesota, pp. 55-141.

Reddy, P.S., M.S. Basu, M.A. Khaleque, M.S. Haque, A. Ali, H. Malek, H. Than, T. Soe, B. Regunathan, B. Mishra, T. Murthy and S. Nigam. 1992. Status of groundnut research and production in South Asia. In: Nigam, S.N. (ed.). Groundnut- a Global Perspective. Proceedings of an Int'l. Workshop 25-29 November 1991. ICRISAT Center, India. ICRISAT.

Sauer, D.B., R.A. Meronuck and C.M. Christensen. 1992. Microflora. In: Sauer, D.B. (ed.). Storage of Cereal Grains and Their Products. Amer. Assoc. Cereal Chemists, Inc. St. Paul, Minnesota, pp. 313-340.

Siriacha, P., K. Kawashima, M. Saito, P. Tan-boon-ek and D. Buangsuwon. 1990. Prevention of Thai maize from the infection by Aspergillus flavus and aflatoxin contamination in various packages. Proc. Jpn. Assoc. Mycotoxicology 32: 41-46.

Wilson, D. and E. Jay. 1976. Effect of controlled atmosphere storage of aflatoxin production in high moisture peanuts (groundnuts). J. Stored Prod. Res. 12: 97-100.

WHO. 1979. Mycotoxins. World Health Organization, Geneva. 
Appendix 1. Average temperature and relative humidity in warehouse during storage of peanuts

\begin{tabular}{lcc}
\hline \hline Month & Temperature $\left({ }^{\circ} \mathrm{C}\right)$ & Relative humidity (\%) \\
\hline July - August & 25.6 & 68.5 \\
September & 26.9 & 66.7 \\
October & 27.4 & 70.4 \\
November & 27.2 & 75.5 \\
December & 26.7 & 78.7 \\
January & 27.3 & 76.9 \\
\hline
\end{tabular}

